\title{
Rethinking prejudice?: Old debates dressed up in new clothes
}

\author{
[ B O O K R E VIE W ]
}

Beattie, Geoffrey (2013) Our racist heart? An exploration of unconscious prejudice in everyday life. London: Routledge. ISBN 9780-415-61299-9 pbk. Pages ix +295

In the current climate of Brexit, Trumpism, Islamophobia, racial profiling by the police, and, closer to home xenophobia, race wars on social media and other reports of racially motivated attacks across the country, Beattie's Our racist heart? An exploration of unconscious prejudice in everyday life (2013) is a timely read. The question of prejudice and its common intersecting configurations through race and class remains a troubling one - more so with regards to race's continued insidiousness and recalcitrance. In its subtle tendencies, prejudice makes itself present in our relationships, our institutions, our selection processes, imaginary and actual social interactions. In our current neo-liberal and blatant conservative political - and apolitical - racial re-enactments, it is perhaps this insidiousness that boggles. In Our racist heart? Beattie tackles an age-old issue that has baffled and captured much social psychological research and work. Revisiting concepts such as implicit and unconscious attitudes, the book attempts a re-engagement of prejudice's content and context.

Structured into three parts, the book attempts to introduce an old debate but with a less common focus. Part 1: Challenged by history, is in many ways a looking back. Beattie lays the foundation for prejudice's unconscious content, challenging dominant
Peace Kiguwa

Department of Psychology University of the

Witwatersrand Johannesburg 
engagements that resist any notion of implicit and unconscious racism. He makes the argument for prejudice's continued salience in our everyday lives and contexts, including our most liberal institutions. The overview further draws attention to the discord and cognitive dissonance that is evident between our thoughts, language and action. Through this, he makes the claim that any worthwhile study of prejudice must go beyond the analysis of language. How are we to explore those reflective modes of thought, instinctive actions and so on that seem to defy linguistic coding? This introduction sets the foundation for thinking about the unconscious and implicit content of prejudice. The rest of the chapters in this section look back in history in other ways - for instance, Early lessons in prejudice takes us back to the author's schooling days, exploring the class and ethnic prejudices that he experienced as a young Irish schoolboy on a scholarship in an elite British school. From the enactments of symbolic violence against wearing the wrong style of socks to inappropriate body language and accent, this chapter is an insightful reminder of Bourdieu's biting critique of the education institution as an effectively violent system to the self, the body and social classes. This section also raises the problematic of tackling institutional racism by challenging and exposing those cultures of practice within the university context that are entrenched in implicit and unconscious biases.

This is a problematic that Beattie returns to in more depth in the last chapter of the book. In Who needs the Negro? a brief historical overview of selection, hiring and recruitment practices and policies (from 1942 to the 60s) are unpacked as a precursor to thinking about current practices and contexts of selection and hiring in the workplace. We are left wondering about the supposed changes that have since taken place: given the influence of our implicit biases - predominantly racial - in how decisions of "worthiness" and competence get made, just how much has changed really? This is the question Beattie wants us to ponder as he takes us into the last chapter of this section. In a recent 2015 panel debate at the Psychological Society of South Africa (PSYSSA) titled "Are we programmed for prejudice?", this very question was troubled in different ways by the panellists. In this debate, the panellists engaged the ideological limitations of attempting to locate prejudice within individuals and social groups, instead preferring to trouble the socio-historical and political function, form and re-enactments of prejudice in society. Beattie takes us on a very different and specific (and perhaps troubling) route that once again calls attention to locating prejudice, its make-up and its cause. Could we - everyone of us - have a racist heart? This Beattie's problematic.

This last chapter presents an overview of the some of the key work undertaken in this field: prejudice as in/visible, ir/rational, Allport's work on categorization and separation in the development of prejudice, re-fencing as a way to maintain prejudiced attitudes, emotion and cognition and evolutionary perspectives on categorizing groups of people 
into "others". Beattie's primary issue with these works concerns the exclusion and undermining of prejudice's implicit and unconscious nature - the very nature, he argues, that makes prejudice recalcitrant even in so-called post-race societies. In so doing he challenges the problematic view of prejudiced individuals as "abnormal" and anomalies in an otherwise colour-blind society. Indeed, by the end of this section, prejudice is demonstrated to be everyone of our problems, imbued in all of us, existing in subliminal ways that render it invisible to many of us. This is an important argument. What is sorely missing in all of this is a socio-historical and material analysis of prejudice's form and pattern. Challenging attempts to locate prejudice in some individuals and not others is a useful critique but this is not enough. Making the claim that prejudice is not only in some of us but all of us is not enough. Missing from this overview and critique is a deeply reflective and critical analysis of what Moreau (2015: 494) describes as "intersectional citizenship". An analysis that draws attention to the myriad ways we may belong to multiple communities simultaneously and experience different layers of vulnerability to prejudice and discrimination. Such an analysis must engage the socio-political ways that prejudice is informed by socio-histories that implicate particular forms of power and which are configured in multiple, contradicting and intersectional citizenship.

Parts II and III of the book continue the overview with a focus on introducing new experimental work on implicit attitudes and unconscious bias using the Implicit Association Test (IAT). Beattie again foregrounds the discussion by presenting historical evidence for implicit race attitudes that influenced racial hiring during the 1970s. Linking this to current practices, he demonstrates the static nature of change - racial stereotypes remain the elephant in the room in many selections processes. It is here that he argues strongly for the influence of unconscious biases in social and workplace interaction. Beattie builds on Allport's work on ambivalent racism - that is holding simultaneous and contradictory views of minorities that are both positive and negative in form. For Beattie, prejudice is not only about self-presentation but may also embody inner conflict for many people related to such contradictory views. He takes issue with Allport's explicit avoidance of the unconscious dimension of prejudice - much like Bourdieu's dismissal of a psychosocial analysis of the unconscious and emotion in engaging habitus. Beattie proposes ways that we may begin to measure this dimension in understanding how prejudice works. Through this, the section lays the groundwork for the last section of the book: Are we implicitly racist?, which provides empirical evidence and discussion for unconscious prejudice. Questioning the traditional IAT's ecological validity (previous tests that used morphed and stereotypical faces of minorities for example), Beattie and his team present new data using revised versions of the IAT that include real faces, and gender representations amongst other factors. The concluding chapter even presents an analysis of Beattie's own implicit race test and returns once again to the role of implicit and unconscious biases in sustaining racism in institutions 
of higher learning. Researchers undertaking work in implicit bias will find this very useful and a much needed conversation on the utility of the IAT in engaging the nuances and form of prejudice. As a teaching tool I found this to be an easily accessible discussion for many students in my undergraduate social psychology lectures. This last section of the book is a bringing together of empirical and theoretical discussions of attitudes, prejudice and implicit bias. Yet again, however, there is much that remains left out. Self-congratulatory in parts, I found the discussion and analysis severely lacking in engaging the interconnections of social categories and identities. How certain groups of people come to be positioned in particular ways, how intersecting identities are lived in complex ways, how we become particular types of people, how the work and analysis of prejudice must examine these complex processes of becoming, everydayness, lived material realities remains largely silent in this narrative. Locating prejudice in all of us and not just some of us, in implicit attitudes and biases, as unconscious manifestation is in the long run only half the picture. To what end do we refine, rehash these debates if we exclude prejudice's configuration in power?

\section{Overall, Our racist heart? An exploration of unconscious prejudice in everyday}

life is a welcome contribution to current socio-cognitive and other work exploring attitudes and implicit biases in everyday interaction. The empirical intersection with theoretical analysis is a welcome engagement. The central thrust of the book however falls short of a critical and socio-political analysis of prejudice in society. In this sense then, Beattie fails to deliver a new debate, but rather presents us a old one dressed up in brand new clothes.

\section{References}

"Are we programmed for prejudice?". PSYSSA Plenary Congress Debate. $21^{\text {st }}$ annual South African Psychology Congress. Johannesburg, 15-18 September, 2015. Panelists: Yaseen Ally, Melanie Judge, Bafana Khumalo, and Peace Kiguwa. Moderator: Eusebius McKaiser.

Moreau, J (2015) Intersectional citizenship, violence, and lesbian resistance in South Africa. New Political Science, 37(4), 494-508. 